\title{
HUBUNGAN PELAKSANAAN TINDAKAN KEPERAWATAN BERDASARKAN KEBUTUHAN DASAR MANUSIA VIRGINIA HANDERSON DENGAN KEPUASAN PASIEN DI RS BHAYANGKARA WAHYU TUTUKO BOJONEGORO
}

\author{
Mei Fitria Kurniati.Ahmad Zainal Abidin. \\ Program Studi Keperawatan Stikes Insan Cendekia Husada Bojonegoro
}

\begin{abstract}
The nurse is obligated to examine the basic human needs for determining the action plan and implementation to be delivered tro the patient. Patient satisfaction is one indicator of the quality of service we provide and patient satisfaction is a capital to get more patients and to get patients loyalty. The purpose of this study is to know the relationship of implementation of nursing actions based on basic human needs from Virginia Handerson with satisfaction of patient at Bhayangkara Wahyu tutuko Bojonegoro Hospital

This research desaign using Cross Sectional. The sampling methode used is Purposive Sampling. A sampling of 23 nurses and 30 patients met the inclution criteria. The variables studied are the independent variables of nursing action and the dependent variable is patient satisfaction. Data were collected using questionnaire and analyzed by using Spearman Rho test with significance level 0,05.

The result showed that all nurses performed a good nursing action that is as much as 23 respondents (100\%).Patient satisfaction data found that most of respondents stated very satisfied that as many as 29 respondents $(96.7 \%)$ and 1 respondent $(3.3 \%)$ expressed satisfaction. The result of Spearman Rho test showed sig. $\rho=0,000$ means $\rho<0.05$ so that is accepted so that there is a relationship of implementation of nursing actions based on basic human needs from Virginia Handerson with satisfaction of patient at Bhayangkara Wahyu tutuko Bojonegoro Hospital.

Nurses should be more active to improve the quality of the implementation of nursing actions by meeting basic human needs as a responsibility in providing professional services to improve patient satisfaction as a service user.
\end{abstract}

Key word: Nursing Action, Basic Human Needs, Patient Satisfication

Abstrak: Perawat mempunyai kewajiban untuk mengkaji kebutuhan dasar manusia, untuk menentukan rencana tindakan dan implementasi yang akan diberikan kepada pasien. Kepuasan pasien merupakan salah satu indikator kualitas pelayanan yang kita berikan dan kepuasan pasien adalah suatu modal untuk mendapatkan pasien lebih banyak lagi dan untuk mendapatkan pasien yang loyal/setia. Tujuan penelitian ini yaitu mengetahui hubungan pelaksanaan tindakan keperawatan berdasarkan Kebutuhan Dasar Manusia dari Virginia Handerson dengan Kepuasan Pasien di Rumah Sakit Bhayangkara Wahyu Tutuko Bojonegoro.

Desain penelitian ini menggunakan metode Cross Sectional. Metode sampling yang digunakan adalah Purposive Sampling. Sampel sejumlah 23 perawat dan 30 pasien yang memenuhi kriteria inklusi. Variabel yang diteliti adalah variabel independen yaitu tindakan keperawatan dan variabel dependen yaitu kepuasan pasien. Data dikumpulkan menggunakan kuesioner dan dianalisis dengan menggunakan uji Spearman Rho dengan tingkat kemaknaan 0,05.

Hasil penelitian menunjukan seluruh perawatmelakukan tindakan keperawatan dengan baik yaitu sebanyak 23 responden (100\%). Data kepuasan pasien didapatkan bahwa sebagian besar responden menyatakan sangat puas yaitu sebanyak 29 
responden $(96,7 \%)$ dan 1 responden $(3,3 \%)$ menyatakan puas. Hasil uji Spearman Rho menunjukkan nilai sig. $\rho=0,000$ berarti $\rho<0,05$ sehingga $\mathrm{H}_{1}$ diterima sehingga ada hubungan Pelaksanaan Tindakan Keperawatan berdasarkan Kebutuhan Dasar Manusia dari Virginia Handerson dengan Kepuasan Pasien di Rumah Sakit Bhayangkara Wahyu Tutuko Bojonegoro.

Hendaknya perawat lebih aktif meningkatkan kualitas pelaksanaan tindakan keperawatan dengan memenuhi kebutuhan dasar manusia sebagai tanggung jawab dalam memberikan pelayanan profesional untuk meningkatkan kepuasaan pasien sebagai pengguna jasa layanan.

Kata Kunci : Tindakan Keperawatan, Kebutuhan Dasar Manusia, Kepuasan Pasien

\section{PENDAHULUAN}

Proses keperawatan adalah metode pengorganisasian yang sistematis dalam melakukan asuhan keperawatan pada individu, kelompok dan masyarakat yang berfokus pada identifikasi dan pemecahan masalah dari respons pasien terhadap penyakitnya. Proses keperawatan digunakan untuk membantu perawat untuk melakukan praktik keperawatan secara sistematis dalam memecahkan masalah keperawatan (Tarwoto \& Wartonah, 2015).

Perawat merupakan tenaga di rumah sakit terbanyak (sekitar 40\%) dan paling banyak berinteraksi dengan pasien. Untuk memenuhi kepuasan pasien, maka apa saja yang menjadi kewajiban dan tanggung jawab perawat merupakan hal yang harus dikaji. Perawat sebagai tenaga kesehatan professional mempunyai kesempatan paling besar untuk memberikan pelayanan kesehatan khususnya asuhan keperawatan yang komprehensif meliputi biologi, psikologi, sosial, dan spiritual (Hamid, 2000 dalam Ristianingsih, 2014).

Virginia Handerson mengemukakan bahwa membantu individu yang sakit \& sehat dalam melaksanakan aktivitas yang memiliki kontribusi terhadap kesehatan \& penyembuhan dimana individu dibantu secara cepat untuk mendapatkan kembali kemandiriannya untuk memenuhi 14 kebutuhan Handerson.Virginia Handerson menegaskan bahwa perawat harus masuk ke dalam kulit pasien, sehingga perawat tahu kebutuhannya dan kemudian mengidentifikasi kebutuhan yang harus divalidasi dengan pasien (Alligood, 2006).

Kepuasan pasien merupakan salah satu indikator kualitas pelayanan yang kita berikan dan kepuasan pasien adalah suatu modal untuk mendapatkan pasien lebih banyak lagi dan untuk mendapatkan pasien yang loyal/setia (Nursalam, 2016).Penelitian Otani dkk di lima rumah sakit di daerah metropolitan St. Louis midMissouri dan bagian selatan Illinois Amerika Serikat menunjukkan bahwa pelayanan yang diberikan oleh staf dan perawat adalah faktor yang paling mempengaruhi tingkat kepuasan pasien (Otani et al, 2009 dalam dalam Andriani\& Putra, 2014).

Pasien sebagai penerima jasa pelayanan menghendaki perawat selalu menjadi care provider yang sesungguhnya. Pemenuhan kebutuhan dasar manusia termasuk kebutuhan oksigen, nutrisi, cairan dan elektrolit, eliminasi, keamanan, kebersihan \& kenyamanan fisik, istirhat \& tidur, kebutuhan gerak \& kegiatan jasmani, spiritual, emosional, komunikasi dan mencegah dan mengatasi reaksi fisiologis (Nursalam, 2016).

Pada saat terjadi penyakit serius, perawat dipandang sebagai pengganti apa kekurangan pasien karena kurangnya kekuatan, kemauan atau 
pengetahuan. Selama fase pemulihan perawat membantu pasien untuk mendapatkan kembali kemandiriannya. Bekerja sebagai mitra, perawat bersama-sama merumuskan rencana keperawatan (Kasron dkk, 2016).Oleh sebab itu, sangat penting setiap institusi pelayanan untuk terus menerus meningkatkan kualitas tindakan keperawatan sehingga pasien akan senantiasa puas dan merasa nyaman dengan tindakan keperawatan yang diberikan oleh perawat.

\section{METODE}

Rancangan penelitian yang digunakan dalam penelitian ini adalah penelitian korelasional. Penelitian ini bertujuanmencari, menjelaskan suatu hubungan korelatif antarvariabel dan menguji berdasarkan teori yang ada. Selanjutnya penelitian ini menggunakan pendekatan cross sectional yaitu menekankan waktu pengukuran/observasi data variabel independen dan dependen hanya satu kali pada satu saat

(Nursalam,2013 )

Penelitian dilakukan pada bulan. 29 Januari 2018 sampai 16 Februari 2018. Populasi pada penelitian ini adalah seluruh perawatdan pasien rawat inap dan di Rumah Sakit Bhayangkara Wahyu

Tutuko

Bojonegoro.Pengambilan sampel penelitian ini menggunakan teknik purposive sampling. Sampel diambil dari perawat dan pasien rawat inap Rumah Sakit Bhayangkara Wahyu Tutuko Bojonegoro dengan kriteria sampel penelitian adalah :

1. Kriteria perawat dalam penelitian ini adalah :

a. Bersedia menjadi responden

b. Perawat yang tidak dalam kondisi sakit

c. Perawat yang tidak sedang cuti d. Perawat yang bekerja di ruang anak, ICU dan penyakit dalam

2. Kriteria pasien dalam penelitian ini adalah :

a. Pasien yang ditunggui oleh keluarga

b. Pasien bersedia untuk diteliti.

c. Pasien indikasi MRS minimal 3 hari.

Jumlah sampel pada penelitian ini yaitu terdiri dari 23 perawat dan 30 pasien.

Adapun analisa data yang digunakan adalah uji Spearman Rho dengan taraf signifikasi 0,05 . Yang selanjutnya diolah dengan menggunakan Software SPSS 16.0 agar uji statistik yang diperolah lebih akurat.

\section{HASIL \& PEMBAHASAN \\ Hasil}

1. Karakteristik Responden Perawat Tabel 1 Distribusi Frekuensi Perawat di RS Bhayangkara Wahyu Tutuko Bojonegoro

\begin{tabular}{|c|c|c|c|}
\hline No & Variabel & Frekuensi & Prosentase \% \\
\hline \multirow[t]{5}{*}{1} & Usia & & \\
\hline & $20-25$ tahun & 6 & 26,1 \\
\hline & 26-30 tahun & 12 & 52,2 \\
\hline & 31-35 tahun & 3 & 13,0 \\
\hline & $36-40$ tahun & 2 & 18,7 \\
\hline \multirow[t]{5}{*}{2} & Pendidikan & & \\
\hline & $\mathrm{S} 1$ & 4 & 17,4 \\
\hline & Keperawatan & & \\
\hline & D3 & 19 & 82,6 \\
\hline & Keperawatan & & \\
\hline \multirow[t]{5}{*}{3} & Ruangan & & \\
\hline & $\mathrm{ICU}$ & 6 & 26,1 \\
\hline & Penyakit & 11 & 47,8 \\
\hline & Dalam & 6 & 26,1 \\
\hline & Anak & & \\
\hline \multirow[t]{5}{*}{4} & Status & & \\
\hline & Pernikahan & & \\
\hline & Belum & 3 & 13 \\
\hline & Menikah & & \\
\hline & Menikah & 20 & 87 \\
\hline \multirow[t]{4}{*}{5} & Jumlah Anak & & \\
\hline & 1 anak & 11 & 47,8 \\
\hline & $\geq 2$ anak & 3 & 13 \\
\hline & $\begin{array}{l}\text { Belum punya } \\
\text { anak }\end{array}$ & 9 & 39,1 \\
\hline \multicolumn{2}{|c|}{ Jumlah } & 23 & 100 \\
\hline
\end{tabular}

Sumber : Kuesioner Februari 2018 
Berdasarkan tabel 4.2 menunjukkan bahwa dari 23 perawat sebagian besar berumur 26-30 tahun yaitu sejumlah 12 responden $(52,2 \%)$, memiliki pendidikan D3 Keperawatan yaitu sejumlah 19 responden $(82,6 \%)$, bertugas di ruangan penyakit dalam yaitu sejumlah 11 responden $(47,8 \%)$, berstatus sudah menikah yaitu sejumlah 20 responden $(87 \%)$ dan memiliki 1 anak yaitu sejumlah 11 responden $(47,8 \%)$.

2. Karakteristik Responden Pasien Tabel 2 Distribusi Frekuensi Pasien di RS Bhayangkara Wahyu Tutuko Bojonegoro
Berdasarkan

tabel 2 menunjukkan bahwa dari 30 pasien sebagian besar berumur 26-35 tahun yaitu sejumlah 9 responden $(30 \%)$, berjenis kelamin perempuan yaitu sejumlah 16 responden $(53,3 \%)$, memiliki diagnosa medis gangguan sistem pencernaan yaitu sejumlah 7 responden $(23,3 \%)$.

3. Karakteristik

Pelaksanaan

Tindakan

Keperawatan berdasarkan Kebutuhan Dasar Manusia dari Virginia Handerson

Tabel 3 Distribusi Frekuensi Berdasarkan Pelaksanaan Tindakan Keperawatan di RS Bhayangkara Wahyu Tutuko Bojonegoro

\begin{tabular}{|c|c|c|c|c|c|c|c|}
\hline \multirow{2}{*}{$\begin{array}{l}\text { No } \\
1 \\
\end{array}$} & \multicolumn{2}{|l|}{ Variabel } & \multirow{2}{*}{ Frekuensi } & \multicolumn{2}{|c|}{ Prosentase $\%$} & & \multirow{4}{*}{$\begin{array}{l}\text { Prosenta } \\
\text { se } \%\end{array}$} \\
\hline & \multicolumn{2}{|l|}{ Usia } & & & No & \multirow{3}{*}{$\begin{array}{l}\text { Pelaksanaan } \\
\text { Tindakan } \\
\text { Keperawatan } \\
\end{array}$} & \\
\hline & \multicolumn{2}{|l|}{$17-25$ tahun } & 1 & 3,3 & & & \\
\hline & \multicolumn{2}{|l|}{ 26-35 tahun } & 9 & 30 & & & \\
\hline & \multicolumn{2}{|l|}{$36-45$ tahun } & 6 & 20 & 1 & Baik & 100 \\
\hline & \multicolumn{2}{|c|}{$46-55$ tahun } & 5 & 16 & 2 & Cukup & 0 \\
\hline & $56-65$ ahu & & 3 & 10 & 3 & Kurang & 0 \\
\hline & \multirow{2}{*}{\multicolumn{2}{|c|}{$>65$ tahun }} & 6 & 20 & & Jumlah $\quad 23$ & 100 \\
\hline & & & & \multicolumn{4}{|c|}{ Sumber : Kuesioner Februari 2018} \\
\hline \multirow[t]{4}{*}{2} & \multicolumn{3}{|c|}{ Jenis Kelamin } & \multicolumn{4}{|c|}{ Berdasarkan tabel 3 menunjukkan } \\
\hline & & 14 & 46,7 & \multirow{3}{*}{\multicolumn{3}{|c|}{$\begin{array}{l}\text { bahwa seluruh perawatmelakukan } \\
\text { pelaksanaan tindakan keperawatan } \\
\text { dengan baik yaitu sebanyak } 23\end{array}$}} \\
\hline & \multirow{2}{*}{\multicolumn{2}{|c|}{ Perempuan }} & \multirow[t]{2}{*}{16} & \multirow[t]{2}{*}{53,3} & & & \\
\hline & & & & & & & \\
\hline \multirow[t]{14}{*}{3} & \multicolumn{2}{|c|}{ Diagnosa Media } & & & \multicolumn{3}{|c|}{ responden $(100 \%)$} \\
\hline & Gangguan & Sistem & 3 & 10 & \multicolumn{3}{|c|}{ 4. Karakteristik Kepuasan Pasien } \\
\hline & \multicolumn{2}{|c|}{ Kardiovaskular } & & & \multicolumn{3}{|c|}{ Tabel 4 Distribusi frekuensi } \\
\hline & Gangguan & Sistem & 1 & 3,3 & \multicolumn{3}{|c|}{ Berdasarkan Kepuasan Pasien di } \\
\hline & $\begin{array}{l}\text { Gangguan } \\
\text { Pencernaan }\end{array}$ & Sistem & 7 & 23,3 & \multicolumn{3}{|c|}{ Bojonegoro } \\
\hline & $\begin{array}{l}\text { Gangguan } \\
\text { Persyarafan }\end{array}$ & Sistem & 3 & 10 & No & $\begin{array}{l}\text { Kepuasan } \\
\text { Pasien }\end{array}$ & $\begin{array}{l}\text { Prosentase } \\
\%\end{array}$ \\
\hline & Gangguan & Sistem & 5 & 16,7 & 1 & Sangat Puas & 96,7 \\
\hline & \multicolumn{2}{|c|}{ Muskuloskeletal } & & & 2 & Puas & 3,3 \\
\hline & Gangguan & Sistem & 4 & 13,3 & 3 & Tližlak Puas & 0 \\
\hline & Endokrin & & & & 4 & Sangat $\quad$ Tidak & 0 \\
\hline & Gangguan & Sistem & 3 & 10 & & $\mathrm{Pl}$ Pas & \\
\hline & Termoregula & & & & Jumla & 30 & 100 \\
\hline & Gangguan & Sistem & 1 & 3 & Sumbe & $3:$ Kuesioner Februari 20 & \\
\hline & $\begin{array}{l}\text { Penglihatan } \\
\text { Gangguan } \\
\text { Hematologi }\end{array}$ & Sistem & 3 & 10 & menui & $\begin{array}{l}\text { Berdasarkan } \\
\text { jokkan bahwa }\end{array}$ & $\begin{array}{r}4 \\
\text { besar }\end{array}$ \\
\hline & er:Kuesio & $r F e b$ & lari 2018 & & $\begin{array}{l}\text { pasien } \\
\text { seban }\end{array}$ & $\begin{array}{l}\text { menyatakan sangat puas } \\
\text { rak } 29 \text { responden }(96,7 \%)\end{array}$ & yaitu \\
\hline
\end{tabular}


5. Tabulasi Silang Berdasarkan Hubungan PerilakuTindakan Keperawatan berdasarkan Kebutuhan Dasar Manusia dari Virginia Handerson dengan Kepuasan Pasien

Tabel 5 Tabulasi Silang Pelaksanaan Tindakan Keperawatan berdasarkan Kebutuhan Dasar Manusia dari Virginia Handerson dengan Kepuasan Pasien di Rumah Sakit Bhayangkara Wahyu Tutuko Bojonegoro.

\begin{tabular}{|c|c|c|c|c|c|}
\hline \multirow{3}{*}{$\begin{array}{l}\text { Pelaksa } \\
\text { naan } \\
\text { Tindaka } \\
\text { n } \\
\text { Kepera } \\
\text { watan }\end{array}$} & \multicolumn{5}{|c|}{ Kepuasan Pasien } \\
\hline & \multicolumn{2}{|c|}{ Sangat Puas } & Puas & \multicolumn{2}{|c|}{ Total } \\
\hline & $\mathrm{N}$ & $\%$ & $\mathrm{~N} \%$ & $\mathrm{~N}$ & $\%$ \\
\hline Baik & 29 & 96,7 & 3,3 & 30 & 100 \\
\hline Jumlah & 29 & 96,7 & 3,3 & 30 & 100 \\
\hline
\end{tabular}

Hasil tabulasi silang pada tabel 5 didapatkan seluruh responden yaitu 23 perawat $(100 \%)$ melakukan tindakan keperawatan dengan baik yaitu 29 responden $(96,7 \%)$ mengatakan sangat puas dan 1 responden $(3,3 \%)$ mengatakan puas.

Hasil Korelasi Pelaksanaan Tindakan Keperawatan berdasarkan Kebutuhan Dasar Manusia dari Virginia Handerson dengan Kepuasan Pasien Berdasarkan hasil ujiSperaman Rho, ditujukkan bahwa hasil nilai Pvalue pada kolom sig (2 tailedS) didapatkan nilai 0.000 lebih kecil dari level of significant $\alpha 0,05 \quad(0,000<$ $0,05)$ maka dengan demikian dapat disimpulkan bahwa $\mathrm{H}_{0}$ di tolak dan $\mathrm{H}_{1}$ diterima. Berarti ada hubungan pelaksanaan tindakan keperawatan berdasarkan kebutuhan dasar manusia dari Virginia Handerson dengan Kepuasan Pasien di rumah sakit Bhayangkara Wahyu Tutuko Bojonegoro.

\section{Pembahasan}

\section{Pelaksanaan Tindakan \\ Keperawatan berdasarkan \\ Kebutuhan Dasar Manusia dari Virginia Handerson \\ Berdasarkan tabel 3menunjukkan} dari 23 perawat didapatkan seluruh responden $(100 \%)$ melakukan tindakan keperawatan dengan baik.

Adapun beberapa faktor yang mempengaruhi hasil penelitian ini adalah umur. Berdasarkan table 1 menunjukkan bahwa sebagian besar perawat $(52,2 \%)$ berumur $26-30$ tahun sebanyak 12 responden. Usia adalah umur yang terhitung mulai saat lahir sampai saat ia berulang tahun. Hurlock (1998) dalam Nursalam dan Pariani (2014) menjelaskan bahwa semakin cukup umur, tingkat kematangan dan kekuatan seseorang akan lebih matang dalam berfikir dan bekerja. Dengan bertambahnya usia maka tingkat perkembangan akan berkembang sesuai dengan informasi yang pernah didapatkan dan juga dari pengalaman sendiri.

Berdasarkan tabel 1 menunjukkan bahwa dari 23perawat sebagian besar responden telah berstatus menikah yaitu sejumlah 20 responden $(87 \%)$.

Data lain menunjukkan terdapat 11 perawat $(47,8 \%)$ telah memiliki 1 anak. Meskipun pada kenyataannya sebagian perawat telah bersatus menikah dan memiliki satu anak, dimana mereka pasti juga memiliki tugas dan peran di rumah sebagai seorang pasangan suami/istri dan orangtua namun mereka tetap bisa menjalankan tugasnya sebagai perawat dengan profesional untuk melakukan tindakan keperawatan. Perawat mampu melakukan proses keperawatan sesuai wewenangnya untuk membantu menyelesaikan masalah pasien. 
Tindakan keperawatan yang dilakukan oleh perawat berdasarkan kebutuhan dasar manusia dari Virginia Handerson yaitu bernafas dengan normal, makan dan minum yang cukup, eliminasi, bergerak dan mempertahankan posisi yang dikehendaki, istirahat dan tidur, memilih pakaian yang tepat, mempertahankan suhu tubuh dalam rentang normal, menjaga tubuh tetap bersih dan rapi, menghindari bahaya lingkungan, berkomunikasi dengan orang lain, beribadah menurut keyakinan. Kebutuhan tersebut diharapkan mampu dipenuhi oleh perawat agar pasien memperoleh kesembuhan dan kesejahteraan. Tindakan keperawatan yang prosentasenya paling baik dilakukan oleh seluruh responden yang terdiri dari 23 perawat $(100 \%)$ bekerja di ruangan ICU, Penyakit Dalam dan Anak ditemukan pada kebutuhan dasar manusia seperti kebutuhan oksigenasi; nutrisi, cairan dan elektrolit; emosional; komunikasi dan fisiologi. Perawat tersebut berupaya untuk mampu memberikan bantuan apa yang menjadi kebutuhan pasien. Pasien yang lemah kondisinya karena sakit dan tidak mampu memenuhi kebutuhannya secara mandiri, akan bergantung pada perawat sampai pasien tersebut mencapai kesembuhannya kembali dan pada akhirnya bisa mandiri. Hal ini sesuai yang dikemukakan oleh Virginia Handerson bahwa pada situasi pasien yang gawat, perawat berperan sebagai pengganti di dalam memenuhi kebutuhan pasien akibat kekuatan fisik, kemauan, atau kemampuan pasien berkurang (Budiono \&Pertami, 2016).

Sebagian besar perawat di rumah sakit Bahayangkara Wahyu Tutuko Bojonegoro sejumlah 17 perawat $(73,91 \%)$ telah memenuhi kebutuhan bergerak dan posisi yang dikehendaki. Data menunjukkan dari 23 perawat, ada
6 perawat yang belum memenuhi kebutuhan bergerak dan mempertahankan posisi yang dikehendaki. Salah satunya untuk melakukan latihan gerak pada klien tidak sadar/kondisi yang lemah dan melakukan mobilisasi pada klien pascaoperasi/kondisi yang lemah. Hal ini merupakan tugas perawat yang perlu mendapat perhatian untuk di implementasikan pada pasien karena memerlukan bantuan perawat untuk bisa melakukan latihan gerak dan mobilisasi. Disini pasien nantinya akan secara berangsur-angsur mendapatkan kembali kemandiriannya untuk melakukannya sendiri. Hal ini sesuai dengan yang dikemukakan oleh Virginia Handerson dengan sebuah model keperawatan yang dikenal dengan "The Activities of Living". Model tersebut menjelaskan bahwa tugas perawat adalah membantu individu dalam meningkatkan kemandiriannya secepat mungkin (Budiono \&Pertami, 2016).

Selanjutnya $86,95 \%$ perawat telah memenuhi kebutuhan pasien untuk beribadah menurut keyakinan. Data yang ada menunjukkan masih ada 3 dari 23 perawat yang belum memotivasi pasien untuk berdoa dan 2 dari 23 perawat belum membantu klien untuk beribadah. Perawat harus berupaya membantu memenuhi kebutuhan spiritual pasien sebagai bagian dari kebutuhan pasien secara komprehensif (Hamid, 2000 dalam Ristianingsih, 2014).

Data menunjukkan $91,30 \%$ perawat telah memenuhi kebutuhan eliminasi pada klien. Data tentang kebutuhan eliminasi menunjukkan ada 2 dari 23 perawat belum menyiapkan alat huknah/gliserin/dulkolac dan pemasangan kateter. Selanjutnya diperoleh data 1 dari 23 perawat belummemperhatikan suhu 
cairan/ukuran kateter, menutup pintu dan memasang selimut, mengobservasi keadaan feses/urine dan mengobservasi reaksi klien. Kebutuhan eliminasi merupakan kebutuhan fisiologis untuk proses buang air kecil dan buang air besar. Sehingga sebagai seorang perawat harus bisa memberikan bantuan untuk memenuhi kebutuhan eliminasi urine dan eliminasi alvi pada pasien. Maryuanni (2015) menuliskan bahwa jika dalam hal berkemih ini, seseorang pasien harus ditolong dalam hal suatu pemakaian alat bantu (seperti pispot/urinal) maka perawat harus bersedia siap membantu.

Pada kebutuhan keamanan diperoleh data 23 perawat mencuci tangan sebelum dan sesudah tindakan serta memakai handschooen pada tindakan pemasangan alat keperawatan, kemudian masih ada 2 dari 23 perawat yang belum memberikan penerangan ruangan/cahaya cukup terang dan 3 dari 23 perawat belum memasang alat pengaman pada klien tidak sadar /gelisah.

Hasil penelitian ini menunjukkan kebutuhan kebersihan didapatkan data 6 dari 23 perawat yaitubelum memandikan klien yang tidak sadar/kondisi yang lemah, sedangkan seluruh perawat sudah mengganti alatalat tenun sesuai kebutuhan/kotor dan merapikan alat-alat klien. Kebutuhan personal hygiene merupakan suatu kebutuhan perawatan diri, yang dibutuhkan untuk mempertahankan kesehatan seseorang, baik secara fisik maupun psikologis (Maryuanni, 2015). Oleh karena itu sangat penting untuk memenuhi kebutuhan kebersihan mulut, rambut, kulit dan badan pasien untuk membuat pasien nyaman selama perawatan dan menunjang proses kesembuhan pasien.

Selanjutnya pada kebutuhan istirahat tidur diperoleh data 23 perawat sudahmengatur posisi yang nyaman pada klien dan menjaga kebersihan lingkungan, namun masih ada 1 dari 23 perawat belum mengatur jam berkunjung. Perawat harus berupaya untuk memenuhi kebutuhan istirahat dan tidur pasien agar dapat mempertahankan status kesehatan secara maksimal. Hidayat dan Uliyah (2016) menyatakan pemenuhan kebutuhan istirahat dan tidur terutama sangat penting bagi orang yang sedang sakit agar lebih cepat memperbaiki kerusakan sel. Apabila kebutuhan istirahat dan tidur tersebut cukup, maka jumlah energi yang diharapkan untuk memulihkan status kesehtan dan mempertahankan kegiatan dalam kehidupan sehari-hari terpenuhi.

\section{Kepuasan Pasien}

Berdasarkan tabel 4menunjukkan dari 30pasien didapatkan 29 responden (96,7\%) mengatakan sangat puas atas tindakan keperawatan yang dilakukan dan 1 responden $(3,3 \%)$ mengatakan puas atas tindakan keperawatan yang dilakukan perawat.

Berdasarkan tabel 2 menunjukkan bahwa dari 30pasien sebagian besar berumur 26-35 tahun yaitu sejumlah 9 responden (30\%). Umur responden sebagian besar adapada usia produktif yaitu 20-50 tahun(Depkes RI, 2007).Usia produktifmerupakan usia yang rentan terhadapkejadian penyakit. Hal ini disebabkankarena orang pada usia produktif jarangmemperhatikan kesehatan, seperti polamakan dan pola hidup yang kurang sehatseperti merokok (Dhianingtyas, 2006 dalam Dewi 2015).Gunarsa (2008) dalam Dewi 2015 mengungkapkan bahwabertambahnya umur seseorang dapatberpengaruh pada emosional ataukepuasan seseorang terhadap jasapelayanan, orang usia tua umumnyalebih bersifat terbuka, 
sehingga pasientua harapannya lebih rendah dari pasienmuda. Hal ini yang menyebabkan pasientua lebih cepat puas terhadap jasapelayanan kesehatan.

Sesuai data tentang jenis kelamin pasien pada tabel 2diperoleh jumlah responden laki-laki dan perempuan hampir sama. Responden laki-laki 14 $(46,7 \%)$ orang dan perempuan 16 orang (53,3\%). Menurut Gunarsa (2008) dalam Dewi (2015), jenis kelamin lakilakidianggap

lebih

fleksibeldibandingkan perempuan terkait dengankepuasan terhadap jasa. Pengukuran tingkat kepuasan pasien terhadap sebuahpelayanan jasa yang diberikan merupakan hal yangpenting dilakukankarena seluruh kegiatan yangdilakukan oleh sebuah perusahaan pelayanan jasaseperti Rumah Sakit, pada akhirnya akan bermuaradalam bentuk kepuasan (Lupiyoadi, 2006 \& Supranto,2011 dalam Andrianni dan Putra 2015).

Seluruh responden $(100 \%)$ yaitu sejumlah 30 pasien menyatakan bahwaperawat bekerjasama dengan tim sejawat, dan tim medis dalam menyelesaikan masalah pasien; perawat mau mendengarkan keluhan pasien dan perawat tidak acuh tak acuh; perawat sopan terhadap pasien, keluarga pasien, tim sejawat perawat dan tim kesehatan lain; perawat menghargai pasien, keluarga pasien, tim sejawat perawat dan tim kesehatan lain dan perawat jujur antara pikiran dan tindakannya.

Pada akhirnya akan menciptakan interaksi yang baik dan hubungan yang harmonis antara perawat dan pasien. Seperti yang dinyatakan Pohan (2013) dalam Anggrianni (2017) kepuasan pasien tidak hanya dari meningkatkan fasilitas lingkungan fisik, tetapi adanya upaya untuk memberikan kepuasan kepada pasien terutama pada proses interaksi antara pasien dengan petugas dalam memberikan pelayanan kesehatan.

Kepuasan pasien tertinggi ditemukan pada aspek courtessy, yaitu seluruh 30 responden (100\%), menyatakan perawat sopan terhadap pasien, keluarga pasien, tim sejawat perawat dan tim kesehatan lain; perawat menghargai pasien, keluarga pasien, tim sejawat perawat dan tim kesehatan lain. Perawat sebagai penolong pasien dalam mengelola asuhan keperawatan hendaknya perawat dapat menjalin hubungan yang baik dengan pasien dan mampu menghubungkan diri dengan lingkungan sosialnya. Hal ini sesuai dengan yang ditulis oleh Kodim (2015) agar dapat membina hubungan yang baik, pertama kali harus menunjukkan sikap yang hangat, menghormati, menerima orang lain apa adanya, empati dan tulus membantu orang lain. Perawat yang memiliki kemampuan hubungan antar manusia yang baik akan memudahkan menjalin hubungan dengan klien maupun anggota tim kesehatan lain.

Selanjutnya kepuasaan terendah ditemukan pada aspek caringdan sincerity $(95 \%)$. Sikap caring perawat tercermin saat perawat siap tanggap bila pasien membutuhkan dan perawat mudah dihubungi; perawat memperhatikan keluhan pasien. Berdasarkan data yang ada tentang aspek caring didapatkan bahwa 29 responden dari total 30 responden mengatakan perawat siap tanggap bila pasien membutuhkan dan perawat mudah dihubungi. Sedangkan 2 responden dari 30 responden mengatakan bahwa ada perawat yang belum memperhatikan keluhan pasien.Penelitian ini mendukung pendapat Larrabee (2004) dalamSenarath, et al. (2013): 11) Anggrainni (2017) menyatakan bahwa, interaksi dengan pasiendianggap 
sebagai penentu utama kepuasan pasien.

\section{Hubungan Pelaksanaan \\ Tindakan Keperawatan \\ berdasarkan Kebutuhan Dasar \\ Manusia dari Virginia \\ Handerson dengan Kepuasan \\ Pasien}

Berdasarkan tabel 5menunjukkan

bahwa seluruh perawat melakukan tindakan keperawatan dengan baik dengan29 responden (96,7\%) mengatakan puas dan 1 responden $(3,3 \%)$ mengatakan puas, beberapa diantaranya karena perawat bekerjasama dengan tim sejawat, dan tim medis dalam menyelesaikan masalah pasien; perawat mau mendengarkan keluhan pasien dan perawat tidak acuh tak acuh, perawat sopan terhadap pasien, keluarga pasien, tim sejawat perawat dan tim kesehatan lain; perawat menghargai pasien, keluarga pasien, tim sejawat perawat dan tim kesehatan lain; perawat jujur antara pikiran dan tindakannya. Perawat akan berupaya seoptimal mungkin untuk mengupayakan kesembuhan dan kesejahteraan pasien. Secara berangsur bila tindakan keperawatan di lakukan dengan sebaik mungkin maka akan meningkatkan kualitas praktik keperawatan. Pada akhirnya kepuasan pasien akan tercapai dengan optimal. Kondisi tersebut sesuai pendapat Kozier (1997) dalam Kodim (2015) bahwa proses keperawatan merupakan pedoman praktik keperawatan profesional, mempuanyai beberapa karakteristik yaitu berpusat pada klien , merupakan pendekatan individu dan spesifik untuk memenuhi kebutuhan klien dan mempunyai tujuan jelas melalui suatu tahapan dalam menigkatkan kualitas asuhan keperawatan.

Virginia Handerson telah mengemukakan bahwa sebagai mitra, perawat dan pasien bersama-sama merumuskan rencana perawatan bagi pasien. Meskipun diagnosisnya berbeda, setiap pasien tetap memiliki kebutuhan dasar yang harus dipenuhi. Hanya saja kebutuhan dasar tersebut dimodifikasi berdasarkan kondisi patologis dan faktor lainnya, seperti usia, tabiat, kondisi emosional, status sosial atau budaya, serta kekuatan fisik dan intelektual (Pertami, 2016)

Proses keperawatan yang efektif akan ditentukan oleh motivasi dan pemahaman perawat akan tugasnya. Apabila motivasi perawat baik untuk memberikan tindakan keperawatan maka asuhan yang diberikan pada pasien akan optimal dan pada akhirnya kepuasaan pasien di intitusi pelayanan tersebut tercapai. Berdasarkan beberapa pendapat ahli (Claude S. George) yang dikutip dari penelitian Zuidah (2006) mengatakan bahwa motivasi seseorang berkaitan dengan kebutuhan meliputi tempat dan suasana lingkungan kerja sehingga penurunan motivasi perawat mengakibatkan hasil kerja yang tidak memuaskan dan hasil tindakan perawat menurun.

Kepuasan pelanggan merupakan startegi jangka panjang yang membutuhkan komitmen yang kuat baik menyangkut dana maupun sumber daya manusia (Tjiptono, 2005 dalam Umniyati, 2010), sebab kepuasan pelanggan dapat menjadi sarana untuk membangun hubungan yang harmonis antara organisasi dengan pelanggannya, dimana pelanggan yang puas akan kembali memanfaatkan jasa pelayanan dan merupakan langkah awal yang baik sehingga terciptanya loyalitas pelanggan yang dapat dijadikan suatu promosi yang membentuk rekomendasi dari mulut ke mulut, reputasi baik di mata pelanggan, dapat meningkatkan keuntungan bagi organisasi tidak hanya sebatas pada klien yang biasa 
menggunakan tapi juga masyarakat secara keseluruhan.

\section{Simpulan}

1. Pelaksanaan tindakan keperawatan berdasarkan Kebutuhan Dasar Manusia dari Virginia Handerson di Rumah Sakit Bhayangkara Wahyu Tutuko Bojonegoromenunjukkan bahwa seluruh perawatmelakukan pelaksanaan tindakan keperawatan dengan baik yaitu sebanyak 23 responden $(100 \%)$.

2. Kepuasan pasien di Rumah Sakit Bhayangkara Wahyu Tutuko Bojonegoro menunjukkan bahwa sebagian besar responden menyatakan sangat puas yaitu sebanyak 29 responden $(96,7 \%)$.

3. Ada hubungan Pelaksanaan Tindakan Keperawatan berdasarkan Kebutuhan Dasar Manusia dari Virginia Handerson dengan Kepuasan Pasien di Rumah Sakit Bhayangkara Wahyu Tutuko Bojonegoro dengan nilai signifikasi $0,000(p<0,05)$.

\section{Saran}

\section{Bagi Responden}

Diharapkan mampu menjadi klien yang aktif dan bekerjasama dalam upaya meningkatkan kualitas asuhan keperawatan di tatanan klinik.

2. Bagi tenaga kesehatan

Hendaknya perawat aktif dalam meningkatkan kualitas pelaksanaan tindakan keperawatan dengan memenuhi kebutuhan dasar manusia sebagai tanggung jawab untuk memberikan pelayanan profesional pada klien.

3. Bagi tempat penelitian

Dalam upaya meningkatkan kualitas pelaksanaan tindakan keperawatan , maka diperlukan dukungan dan kerjasama yang baik dari pihak rumah sakit kepada tenaga kesehatan untuk meningkatkan kepuasaan pasien sebagai pengguna jasa layanan.

4. Institusi Pendidikan

Institusi pendidikan dapat meningkatkan kualitas pengembangan kurikulum melalui penambahan literatur, khusus yang berkaitan dengan pelaksanaan tindakan pelaksanaan tindakan keperawatan berdasarkan kebutuhan dasar manusia dari Virginia Handerson dan kepuasaan pasien.

5. Peneliti selanjutnya

Diharapkan hasil penelitian ini dapat digunakan sebagai acuan untukmelakukan penelitian dan sebagai pertimbangan bagi peneliti yang akan datang tentang pelaksanaan tindakan keperawatan berdasarkan kebutuhan dasar manusia dari Virginia Handerson dan kepuasaan pasien.

\section{Keterbatasan Penelitian}

1. Penelitian ini hanya dilakukan di tiga ruangan di Rumah Sakit Bhayangkara Wahyu Tutuko yaitu ruang anak, ruang penyakit dalam dan ICU

2. Tindakan pelaksanaan keperawatan belum sepenuhnya dilakukan observasi secara langsung namun berdasarkan tindakan keperawatan yang telah dilakukan pada pasien dalam tiga hari terkakhir.

Daftar Pustaka

Alligood,M.R., Tomey, A.M. (2010). Nursing theorists and their work. Mosby

Alligood, Martha Raile. (2006). Nursing theory: utilization and application. Elsevier-Mosby

Andriani, A., \& Putra, H. A. (2014). Faktor-Faktor Yang Berhubungan Dengan Kepuasan Pasien Dalam Pelayanan Keperawatan Di Ruang Rawat Inap Interne Pria Dan Wanita Rsud Dr. Achmad Mochtar 
Bukittinggi

2014. 'AFIYAH, 1(2).

Anggrianni, S., Adji, I. S., THT-KL, S., \& Amin Mustofa, S. (2017). Evaluasi Kepuasan Pasien Rawat Inap Dan Rawat Jalan Terhadap Pelayanan Gizi Pasien Diet Diabetes Mellitus Di RSU PKU Muhammadiyah Bantul Yogyakarta (Doctoral dissertation, Universitas Muhammadiyah Surakarta).

Budiono., Pertami, S.U. (2016). Konsep Dasar Keperawatan. Jakarta : Bumi Medika

Dewi, Aulia U., Astuti, Rukma., Werdani, K. E. (2015). Hubungan Waktu Tunggu Pendaftaran dengan Kepuasan Pasien di Tempat Pendaftaran Pasien Rawat Jalan (TPPRJ) RSUD Sukoharjo.

Hidayat, A.Aziz Alimul., Uliyah, Musrifatul. (2016). Buku Ajar Ilmu Keperawatan Dasar. Jakarta : Salemba Medika

Kasron dkk. (2016). Teori Keperawatan dan tokohnya. Jakarta : CV Trans Info Media

Kodim, Yulianingsih. (2015). Konsep Dasar Keperawatan. Jakarta: CV.Trans Info Media

Maryunani, Anik. (2015). Kebutuhan Dasar Manusia. Bogor : In media

Nursalam. (2012). Manajemen Keperawatan Aplikasi dalam Praktik Keperawatan. Profesional. Jakarta :Salemba Medika. (2013). Metodelogi Penelitian Ilmu Keperawatan Pendekatan Praktis. Jakarta: Salemba Medika

Nursalam \& Pariani. (2014). Pendekatan Praktis Penyusunan Metodologi Riset Keperawatan. Surabaya : Sagung Seto.
Pohan, Imbalo S. (2013). Jaminan Mutu Layanan Kesehatan. Jakarta: EGC.

Ristianingsih, D., \& Cahyu Septiwi, I. (2014). Gambaran motivasi dan tindakan keperawatan dalam pemenuhan kebutuhan spiritual pasien di ruang ICU PKU Muhammadiyah

Gombong. Jurnal Ilmiah

Kesehatan Keperawatan, 10(2).

Sastroasmoro, S \& Ismail, S. (2014). Dasar-dasar Metodologi Penelitian Klinis. Edisi ke-3. Jakarta:Sagung Seto.

Siokal, Brajakson dkk. (2017). Falsafah dan Teori dalam Keperawatan. Jakarta : CV Trans Info Media

Tarwoto \& Wartonah. (2015). Kebutuhan Dasar Manusia dan Proses Keperawatan. Jakarta : Salemba Medika

Umniyati, Helwiyah. (2010). Kepuasan Pasien Pelayanan Kesehatan di Puskesmas Kecamatan Tanjung Priok Jakarta Utara tahun 2009. Jurnal Kedokteran Yarsi (18)1 